\title{
CURRÍCULO DE CIÊNCIAS: PROFESSORES E ESCOLAS DO CAMPO
}

\author{
Lívia de Rezende Cardoso* \\ Maria Inez de Oliveira Araújo**
}

RESUMO: Resultante do movimento "Por uma Educação do Campo", a escola do campo é entendida como lugar em que se produz conhecimento a partir da relação direta com a cultura que os sujeitos estabelecem entre si e com o meio onde vivem. Nessa perspectiva, buscamos investigar a seleção dos conteúdos realizada pelos professores de Ciências de escolas do campo, tendo como ferramentas de coleta de dados entrevista e questionário. Constatou-se que o currículo é construído por eles a partir de uma seleção dos conteúdos do livro didático adotado. Embora poucos professores tenham demonstrado pequenos avanços ao preocuparem-se com um currículo a partir do contexto local e que questione as práticas cotidianas em comunidade, consideramos que essa não é uma prática intencional.

Palavras-chave: Educação do Campo, Ensino de Ciências, Currículo Escolar.

\section{SCIENCE CURRICULUM: TEACHERS AND RURAL SCHOOLS}

ABSTRACT: As a result of the movement "Por uma educação do Campo" - in Brazil -, the newrural school shall be understood as a place where knowledge is made from a direct relationship with the culture that people establish among them and with the place where they live. From this perspective, we aim to investigate the selection of contents carried out by Science teachers from rural schools, using interviews and questionnaires as research tools. It was verified that they construct the curriculum from a selection of contents by the adopted didactic book. Even though only a few teachers have showed small advances by trying to implement considerations from the local context and the everyday community life in the curriculum, we consider that this is not an intentional practice.

Keywords: Rural Education, Sciences Teaching, School Curriculum. 


\section{INTRODUÇÃO}

Historicamente, a disciplina escolar Ciências sempre teve a ciência ocidental moderna como referência no processo de seleção de saberes legítimos, servindo como ferramenta de modernização da cultura. Ao reconhecer o conhecimento científico como expressão máxima do discurso dominante da atual sociedade, segundo Lopes (1997), despreza-se a cultura popular, considerando-a inferior. Ao mesmo tempo, de acordo com El-Hani e Sepúlveda (2006), tem-se ensinado uma ciência supostamente neutra, desprovida de implicações sociais ou de compromissos éticos, cujos modelos explicativos tentam construir uma descrição fiel e correta da realidade, uma verdade inquestionável.

Esquece-se, nesse espaço, que os conhecimentos científico e popular precisam ser entendidos como complementares, de maneira a se qualificarem, modificando as práticas de seus possuidores, que passam a tomar como base tanto práticas milenares, como inovações técnicas. Segundo Krasilchik e Marandino (2004, p. 31), "o público, seus conhecimentos, suas concepções, suas necessidades devem sim nortear as escolhas sobre o quê e como realizar a alfabetização científica”. Perceber a alfabetização científica em uma perspectiva cultural, segundo as autoras, implica buscar parcerias para ampliar as oportunidades de acesso e de produção de significados sobre o conhecimento científico pela população.

A priori, as escolas são representantes formais em estabelecer a tradução dos conteúdos científicos para um público variado, principalmente por meio dos professores de Ciências. Para Delizoicov et al. (2002, p. 33), esse desafio não pode ser enfrentado com as mesmas práticas pedagógicas da escola de poucos e para poucos de décadas atrás, pois "a socialização, as formas de expressão, as crenças, os valores, as expectativas e a contextualização sociofamiliar dos alunos são outros". Muda-se, com tal visão, o arranjo do currículo da disciplina Ciências, no qual haveria interação de outros elementos de modo a provocar novas análises de implicações sociais, de valores e de significados aos conceitos científicos em função da realidade dos educandos. Assim, assuntos das ciências ganham outras dimensões: histórica, social, cultural, política e econômica.

Por conseguinte, deixa-se de acreditar na ideia de um ensino de Ciências como mera transmissão de informações, termos científicos e temas sem significados, o que constituiria o que Auler e Delizoicov (2001, p. 07) denominaram de uma alfabetização científica reducionista: "transmissão unidirecional do conhecimento científico que [...] fundamenta-se numa postura pouco crítica em relação às implicações da CT [Ciência e Tecnologia] na sociedade". De acordo com Chassot, a ciência precisa ser entendida como uma linguagem construída pelos homens para explicar o mundo natural. Percebermos "essa linguagem (da ciência) como entendemos algo escrito numa língua que conhecemos (por exemplo, quando se entende um texto escrito em português) é podermos compreender a linguagem na qual está (sendo) escrita a natureza" (2003, p. 13). Desse modo, ser alfabetizado na ciência é saber fazer uma leitura crítica dos fenômenos que cercam nossa vida 
diária. Dessa maneira, estaríamos pensando em uma alfabetização científica que desenvolvesse uma melhoria na vida cotidiana, por meio da resolução de problemas de necessidades básicas e, ao mesmo tempo, da crítica às implicações que envolvem ciência e sociedade.

Foi a partir dessas concepções de ensino de Ciências e de ciência que lançamos nosso olhar sobre o currículo escolar dessa disciplina em escolas do campo, compondo a pesquisa de mestrado de uma das autoras deste trabalho. Para o presente artigo, analisamos dados que respondem às seguintes questões: que temas científicos são mais priorizados pelos professores e quais suas razões ao fazerem isso no currículo de Ciências? Quais saberes têm voz nesse processo? Como é estabelecida a ligação entre a ciência ensinada e os conhecimentos de tradição? Desse modo, objetivamos analisar o processo de elaboração do currículo escolar por parte dos professores pesquisados.

As escolas do campo analisadas nesta pesquisa estão situadas em povoados de Porto da Folha-SE. Representante do alto sertão sergipano por apresentar problemáticas sociais comuns às encontradas em outras cidades localizadas nessa região, esse município foi escolhido por ser o território com mais escolas na zona rural, segundo dados do INEP (2008). Dessa forma, após conhecer a lista com as escolas municipais - cedida pela Secretaria Municipal de Educação - e entrar em contato, pessoalmente e por telefone, com coordenadores, diretores e professores, houve o retorno de cinco - representados aqui por P1, P2, P3, P4 e P5 - de um universo de nove pessoas que lecionavam a disciplina Ciências nos anos finais do Ensino Fundamental. Todos os professores pesquisados nasceram na sede daquele município, onde dois ainda residem mesmo ensinando nos povoados mais distantes, enquanto outros três sempre viveram e ensinaram nos povoados onde lecionavam até o momento da pesquisa.

A coleta de dados foi feita por meio de uma entrevista gravada e, posteriormente, transcrita, com cada professor - duração média de 75 minutos - para questionar sobre formação inicial/continuada; currículo praticado e contextualização dos conteúdos que eles realizavam. De acordo com Mazzotti e Gewandsznajder (1999), a entrevista possibilita abordar temas complexos, dos quais o entrevistador está interessado em compreender o significado atribuído pelos entrevistados a eventos, situações e processos. Para tanto, nos valemos de um tipo de entrevista, a semiestruturada, pois, segundo Flick (2002, p. 89), com esse tipo de entrevista "é mais provável que os pontos de vista dos sujeitos entrevistados sejam expressos em uma situação de entrevista com um planejamento relativamente".

Após análise dos dados obtidos na entrevista, sentimos a necessidade de esclarecer mais alguns pontos na abordagem de assuntos citados, como água, solo e alimentação. Assim, por entendermos que os professores podiam ficar mais à vontade e ter mais tempo de reflexão, optamos pela aplicação de questionário com questões objetivas e dissertativas. Afinal, de acordo com Marconi e Lakatos (2006, p. 203), esse é um "instrumento de coleta de dados, constituído por uma série ordenada de perguntas, que devem ser respondidas por escrito e sem a presença do entrevistador". 


\section{O CURRÍCULO ESCOLAR DE CIÊNCIAS E AS ESPECIFICIDADES DO CAMPO}

Ao fazer um breve histórico das correntes que influenciaram os estudos sobre currículo no Brasil, Santos e Paraíso (1996, p. 03) afirmam que nos anos de 1970 havia um predomínio do pensamento americano, sendo o currículo entendido como "a especificação dos objetivos da educação considerados desejáveis e a definição dos conteúdos a serem transmitidos na escola para se atingirem tais objetivos". Nas décadas seguintes, tal conceito de currículo é reformulado, passando a ser compreendido como "todas as experiências e conhecimentos proporcionados aos estudantes no cotidiano escolar. [...] é tanto um território de produção ativa de cultura como um campo de contestação cultural" (SANTOS; PARAÍSO, 1996, p.03). Nas palavras de Silva (1996, p. 90):

O currículo não é o veículo de algo a ser transmitido e passivamente absorvido, mas o terreno em que ativamente se criará e produzirá cultura. O currículo é, assim, um terreno de produção e política cultural, no qual os materiais existentes funcionam como matéria prima de criação, recriação e, sobretudo, de contestação e transgressão.

Esse autor entende, ainda, o currículo como sendo "sempre o resultado de uma seleção: de um universo mais amplo de conhecimento e saberes seleciona-se aquela parte que vai constituir, precisamente, o currículo" (SILVA, 2002, p. 15). Devido a esse fator, de acordo com Moreira e Silva (1995, p. 7-8), é que "o currículo não é um elemento inocente e neutro de transmissão desinteressada do conhecimento social”. Em tal concepção crítica de currículo - na qual se embasa a presente pesquisa -, segundo Lopes (2004, p. 111), "o currículo é fruto de uma seleção da cultura e é um campo conflituoso de produção de cultura, de embate entre sujeitos, concepções de conhecimento, formas de entender e construir o mundo". Como consequência, a autora entende que o currículo não se resume aos documentos escritos pelas instâncias governamentais - mesmo reconhecendo seu poder privilegiado -, mas inclui os processos de planejamento em múltiplos espaços e por múltiplos sujeitos no corpo social da educação, pois considera que as práticas e propostas desenvolvidas nas escolas também são produtoras de sentidos para as políticas curriculares. No entanto, Macedo (2006) atenta para a necessidade de a pesquisa educacional entender o currículo para além das dicotomias currículo oficial e currículo praticado, pré-ativo e ativo, salientados por Goodson (1995).

Foi a partir de tais discussões críticas que surgiram os debates sobre currículo e campo. Afinal, a realidade da educação do campo estava relacionada a ações públicas, de acordo com Batista e Moraes (2008), omissas e inadequadas ao longo da história, resultando em uma exclusão educacional que se manifesta nos altos índices de reprovação, repetência, evasão, distorção série-idade, existência de jovens fora da escola e na situação de analfabetismo. Entretanto, por intermédio dessa mesma escola, a mudança é uma possibilidade. A escola do campo não precisa ser o lugar apenas de reprodução do código, dos controles e das práticas - os saberes hegemônicos (BERNSTEIN, 1996), mas o lugar que, a partir de suas próprias 
contradições, é potencialmente o lugar de saberes contra-hegemônicos.

Assim, Fernandes (2004) traz as duas formas de pensar a escola no e do campo: enquanto a primeira está ligada a uma pedagogia tradicionalmente ruralista de dominação, a segunda se propõe a construir uma pedagogia que se baseie nas diferentes experiências dos sujeitos. Mas, sem dúvidas, essa é ainda uma proposta que batalha para se estabelecer de fato. De acordo com Arroyo (2004), o tratamento da Educação do Campo vem mudando e já começa a se reconhecer sua especificidade, mas ainda é urgente um outro tratamento público do direito dos povos do campo à educação.

É entendendo a educação, segundo Fernandes (2004, p. 23), como sendo "processo de formação humana, que constrói referências culturais e políticas para a intervenção das pessoas e dos sujeitos sociais na realidade, visando a uma humanidade mais plena e feliz", que Caldart (2004, p.110) apresenta um conceito de escola do campo:

Uma escola do campo não é, afinal, um tipo diferente de escola, mas sim é a escola reconhecendo e ajudando a fortalecer os povos do campo como sujeitos sociais, que também podem ajudar no processo de humanização do conjunto da sociedade, com suas lutas, sua história, seu trabalho, seus saberes, sua cultura, seu jeito.

Com essa perspectiva, os diversos movimentos sociais desencadearam debates em torno da situação. Assim, surgiu o movimento "Por uma Educação do Campo", a partir do qual a escola do campo é compreendida como um lugar em que se produz o conhecimento a partir da relação direta com a cultura que os sujeitos estabelecem entre si e com o meio onde vivem. Assim, os sujeitos do campo passaram a entender que a escola da maneira como está não tem lugar para eles, pois "sua estrutura formal não permite o seu ingresso, ou porque sua pedagogia desrespeita ou desconhece a sua realidade, seus saberes, suas formas de aprender e ensinar" (CALDART, 2004, p. 93).

De acordo com Martí (2004, p. 60), "trabalhar na terra, tirar da terra a sua existência, exige conhecimentos que são construídos nas experiências cotidianas e na escola". Daí porque os movimentos sociais defendem uma educação do campo que considere e incorpore os saberes dos camponeses, suas culturas. A necessidade de se possuir domínio também sobre o conhecimento científico é incontestável, não só para a garantia de uma vida melhor, mas igualmente para se posicionar criticamente frente a inúmeras situações, conferindo juízo a elas segundo questões éticas e culturais. Tais situações influenciam desde o contexto de uma comunidade até conjunturas com proporções mundiais, indo das questões de saúde pública falta de saneamento básico, abastecimento de água inadequado, problemas com segurança alimentar - até questões de cunho ecológico - desmatamento, queimadas, poluição e esgotamento do solo.

Perceber o currículo de Ciências em uma perspectiva cultural, segundo Krasilchik e Marandino (2004), implica buscar parcerias para ampliar as oportunidades de acesso e de produção de significados sobre o conhecimento científico 
pela população. Isso nos faz refletir sobre que temas são necessários conhecer, bem como no fato de que nem todo conhecimento é fundamental para os variados grupos sociais existentes. Muda-se, com essa visão, então, a configuração do currículo da disciplina Ciências, no qual haveria interação de outros elementos, de modo a provocar novas análises de implicações sociais, de valores e de significados aos conceitos científicos em função da realidade dos educandos. Passaremos, então, a analisar os dados das entrevistas e dos questionários que evidenciam o nível de importância atribuída pelos professores pesquisados em alfabetizar cientificamente seus alunos das escolas do campo. Nessa escrita, nos detivemos ao que dizem os professores sobre o que fazem com o currículo escolar de Ciências produzido por eles. Buscamos entender a seleção dos conteúdos, os saberes que servem de referência nesse processo e os temas citados como sendo os de maior relevância para localidade.

\section{CRITÉRIOS DE SELECฺ̃̃O E EXCLUSÃO}

Os professores pesquisados possuem formação em Ciências Biológicas Licenciatura (02) ou Pedagogia (03), obtida em universidades ou faculdades particulares do estado de Sergipe e Alagoas, com exceção de um - Universidade Federal de Sergipe. A maioria (04) leciona não só a disciplina Ciências - sendo esta a sua ocupação principal -, mas também disciplinas como Português, Religião e Artes, de modo a cumprirem suas cargas horárias nas escolas. O tempo de magistério desses professores variou entre nove (9) e vinte e seis (26) anos, como podemos verificar no quadro 01, sempre em escolas dos povoados do município de Porto da Folha-SE. Todos nasceram na sede do município e dois moram lá até hoje, mesmo ensinando nos povoados mais distantes. Por sua vez, os outros três professores sempre viveram e ensinaram nos locais onde estão lecionando hoje.

Inicialmente, buscou-se perceber os critérios através dos quais os professores de Ciências selecionavam os conteúdos escolares, bem como as razões dessa escolha, para entender o currículo produzido por eles. Assim, eles foram questionados sobre em que se baseavam ao pensar no currículo da disciplina ministrada, se existia alguma relação de conteúdos pronta ou se faziam uma relação própria ao planejarem o ano letivo. Com as respostas, constatou-se que nenhum professor utiliza documentos oficiais como eixo norteador das decisões, tais como a Lei de Diretrizes e Bases da Educação Nacional em vigor e os Parâmetros Curriculares Nacionais, além de não se preocuparem em evidenciar a concepção de currículo que possuíam. O documento de base é o livro didático, sendo que dois deles fazem uso exclusivo desse recurso, como fica explícito ao afirmar: "a gente faz o plano no início do ano e tudo é de acordo com o livro didático" (P1).

Ainda que partindo desse mesmo recurso, os outros professores afirmaram trazer alguns complementos. Dois professores declararam adicionar elementos de outras fontes, tais como internet, televisão e rádio, mas sem evidenciar o 
que é priorizado com esses ambientes. Um professor afirmou que poderia adicionar ou retirar algum conteúdo da lista do livro didático, pois busca partir "também de algum conbecimento deles, da realidade deles" (P5). Nesse aspecto, Caldart afirma que (2003, p. 63) "é a escola que deve ajustar-se, em sua forma e conteúdo, aos sujeitos que dela necessitam; é a escola que deve ir ao encontro dos educandos, e não o contrário". Ela assegura, ainda, que quando isso não ocorre, há uma falta de sensibilidade pedagógica em entrar em movimento com os grupos sociais de modo que a escola não se feche em um jeito de ser que desumaniza pessoas.

Como a figura do livro didático utilizado pela escola estava muito presente na fala deles, pedimos que fizessem uma análise do mesmo e refletissem se estavam satisfeitos com ele e quais as razões. Assim, três demonstraram certa satisfação, ou por serem os livros adaptados à realidade local ou por trazerem conteúdos ou práticas que desconheciam. Essa reflexão contraria o que muitos estudiosos afirmam sobre a inadequação dos livros às diversas realidades brasileiras. Talvez esse seja um indício de que, mesmo conhecendo o contexto da comunidade em que estão inseridos, os professores pesquisados não conseguem dar uma visão crítica aos fatos, que é conseguida a partir da alfabetização científica.

De modo oposto, dois professores demonstraram insatisfação, que foi justificada pelo distanciamento da realidade de seus alunos. Um deles afirma: "o livro traz exemplos de solo, de frutas, de climas que não são daqui. Então, eles dizem que não querem saber disso porque não existe aqui" (P5). Podemos questionar aqui o fato desses dois professores evidenciarem que os livros não se adaptam - mostrando um certo discernimento sobre o que interessa aos seus alunos ao sinalizar a proximidade que fazem disso com o ambiente - mas, mesmo assim, seguem o currículo neles contido.

Essa centralidade atribuída ao livro didático acarreta em algumas funções para esse recurso: guiar o professor na organização, desenvolvimento e avaliação de sua prática pedagógica em sala de aula (CARNEIRO; MOL, 2005). Além disso, Macedo (2004) destaca que a vinculação entre currículo e livro didático já é bastante salientada na literatura, constituindo-se um "vínculo tão forte que tem justificado que políticas, tanto as propostas pelo Banco Mundial quanto as implementadas em países como o Brasil, dêem especial atenção a este dispositivo cultural"' (p. 106). Assim, diversas pesquisas no Brasil têm mostrado, segundo Núñez et al. (2002), como o livro didático passou a ser o principal controlador do currículo. Os professores utilizam o livro como instrumento principal que orienta o conteúdo a ser administrado, sua sequência, as atividades e a avaliação para o ensino das Ciências. Fato preocupante ante à conclusão de Maia (1983, p.17) que, a partir da avaliação dos livros didáticos utilizados em escolas do campo, encerra: “os livros disponíveis são, por sua vez, totalmente inadequados, pois empregam vocabulário de difícil compreensão e textos referidos a experiências muito distantes da zona rural".

Em seguida, tivemos o intuito de explorar os critérios de inclusão e de exclusão dos conteúdos utilizados pelos professores. Por afirmarem que se guia- 
vam pelo o que o livro didático trazia, foram questionados se conseguiam ensinar todos os conteúdos. Eles, por sua vez, alegaram que não, e deram as mais variadas justificativas: insuficiência de recursos didáticos, falta de tempo destinado às aulas de Ciências, ou por serem muitos os conteúdos a serem trabalhados ou pelo uso de suas aulas para fins extra classe, e a falta de aprendizagem dos alunos. Portanto, nenhum professor justificou essa não abordagem de todos os conteúdos, pelo fato de achar desnecessários certos temas para seus alunos. Assim, não estão de acordo com a Declaração Final da II Conferência Nacional Por Uma Educação do Campo (2004): "currículos são deslocados das necessidades e das questões do campo e dos interesses dos seus sujeitos". Eles deixaram implícito em seus discursos que o apropriado é ensinar todos os assuntos do livro, buscando justificativas para explicar o porquê de o não fazerem.

Tentando entender os motivos que os levam a escolher alguns conteúdos e excluir outros por não dar tempo de abordar todos eles, foi pedido que imaginassem uma situação em que só tivessem um mês para ministrar todo o conteúdo de uma série. Como obviamente não teriam como fazer tudo isso, foram perguntados sobre o que eles fariam nessa situação. As justificativas de dois professores oscilaram entre uma possível necessidade que os seus alunos teriam e a afinidade que possuem com os conteúdos. Ao exaltarem essa segunda ideia, desconsideraram o que seria, de fato, importante para os alunos aprenderem.

Por outro lado, dois professores relacionaram os conteúdos por serem compatíveis com o cotidiano dos alunos, pois, segundo um deles, "quando você tá falando de um negócio que eles conhecem, eles prestam atenção. Olha não é só ensinar o que eles sabem, mas épartir disso å̀' (P5). De modo semelhante, o professor 4 usa o critério proximidade com o ambiente local, trazendo exemplos: "Eu dava ecossistema, o assunto da sexta série, porque trabalha com a questão do desmatamento e isso preocupa aqui, sobre a transposição do rio São Francisco" (P4).

Ficou evidente na fala de todos os professores, durante algum momento da entrevista, o fato de que os alunos aprendem com maior facilidade quando se ensina algo aproximado da realidade vivida por eles. Quando ocorre o contrário, os estudantes apresentam problemas com o aprendizado de Ciências, talvez porque os professores não conseguem aproximar a linguagem da ciência a fatos concretos do contexto local, fazendo com que os educandos não vejam sentido no conteúdo científico ensinado. Essa capacidade de reconhecimento dos critérios, Bernstein atribui à familiaridade que o aluno tem com o contexto pedagógico em seu lar. Segundo esse autor (1996, p. 244), a prática pedagógica (família, comunidade, amigos) posiciona o indivíduo: “aqueles que apropriarem o 'texto privilegiante' terão, provavelmente, recebido em casa uma versão da prática pedagógica oficial”.

Isso seria a relevância dos significados dependendo da base material do sujeito. Assim, os alunos de classe média geralmente reconhecem melhor os critérios utilizados na escola por receberem no lar a prática pedagógica oficial, bem como as condições para que isso ocorra, como, por exemplo, silêncio, local de estudo apropriado, tempo disponível para estudos em casa. Em situação oposta, 
os alunos da classe pobre terão maior dificuldade em reconhecer os critérios, gerando o fracasso escolar. Assim, para Bernstein (1996), o sucesso ou o fracasso escolar tem relação, respectivamente, de continuidade ou descontinuidade entre os discursos e as práticas da família e da escola.

Os professores pesquisados mostraram-se bastante influenciados por fatores externos, por um currículo hibridizado, ambíguo e descontínuo do livro didático. Apesar de abrirem espaço para a manifestação da cultura, não agem como efetivos produtores culturais, que criam meios por meio do currículo escolar para que os estudantes possam vislumbrar o caráter socialmente construído de suas experiências, de seus conhecimentos e do conhecimento científico, "num mundo extremamente cambiante de representações e valores” (GIROUX, 1995, p. 101). Reflexões feitas por Moreira e Candau (2003, p. 156) mostram que algumas estratégias pedagógicas são necessárias ao professor que adentra a sala de aula atual, "invadida por diferentes grupos sociais e culturais, antes ausentes desse espaço". Uma educação atenta à diversidade cultural e à diferença precisa adotar as práticas pedagógicas multiculturais, fazendo uma ancoragem histórica e social dos conteúdos, bem como desempenhar um papel de crítico cultural e combater discriminações.

\section{TENSÃO ENTRE SABERES}

Entendendo a ciência como produção cultural, construída em diálogo com outros sistemas culturais, buscamos averiguar se os professores consideravam ou não os conhecimentos prévios dos estudantes ao abordarem os conteúdos. Assim, questionamos, quanto aos saberes populares, se os alunos trazem algum, se há ligação com a disciplina e se esses saberes contribuem ou atrapalham suas aulas. Isto porque, segundo Freire (1992, p. 86), "a localidade dos educandos é o ponto de partida para o conhecimento que vão criando no mundo", sem esquecer o currículo como "espaço-tempo de fronteira em que discursos globais e locais negociam sua existência, permeado por relações interculturais e por um poder oblíquo e contingente" (MACEDO, 2006, p. 106).

Ao afirmar "trazem, eles trazem. Principalmente quando eu pergunto 'dê sua opinião', às vezes não tem nada a vê com o assunto, mas muitas vezes dá para juntar", o professor 4 evidencia que os alunos apresentam seus conhecimentos e experiências em sala de aula. Além disso, os entrevistados declararam utilizá-los nas aulas de modo que, na maioria das vezes, conseguem realizar uma ligação entre esses saberes, como exemplifica o professor 5: "Uma vez eu dei as fases da lua, ai eles já sabiam lua cheia, lua nova, mas eles não sabiam o tempo de uma pra outra, eles sabiam identificar mas não sabiam quanto tempo durava, então ficou bem mais fácil dá o assunto pra eles".

Esses professores estabelecem, então, o modelo de ensino "stricto sensu" proposto por Chevallard (1991). Segundo esse autor, haveria um entorno social formado pelos cientistas, família dos estudantes e as instâncias políticas - que cerca as relações didáticas e o que estabeleceria uma relação entre esses dois seria a noos- 
fera - formada por agentes ou agências especializados no trabalho de transposição didática mais diretamente. Além disso, a valorização da pura produção de conhecimento científico em detrimento das manipulações necessárias ao processo de socialização, sugere a impossibilidade do próprio funcionamento das sociedades. Outro ponto importante é que, mais uma vez, eles demonstraram que os alunos conseguem entender melhor os conteúdos científicos quando estes são recontextualizados para realidade em que vivem. Isso corresponde ao que Chevallard (1991) se referiu sobre os objetos de ensino. Para ele, este deve remeter-se àquilo que é conhecido pelo aluno, mesmo sendo algo novo e, quando não conseguem realizar algum tipo de reconhecimento ou identificação com os saberes que já dominam, o estranhamento pode ocorrer em proporções que inviabilizam o aprendizado.

Pode-se constatar, também, que a maioria dos professores preocupa-se em superar as ideias vinculadas ao senso comum da comunidade. Quando um dos professores afirmou "aquele conhecimento que agente tem no dia a dia não pode ser menosprezado, porque aqui tem muito isso de cultura popular, mas as vezes quando você estuda você vê que não é bem assim, e eles acreditam tanto que acabam trazendo pra sala de aula" (P1), evidenciou-se uma atenção para modificá-lo e enriquecê-lo com o conhecimento científico. Nesse ponto, devemos atentar para o fato de que a educação no campo se dá quando são levados em conta os conhecimentos de tradição e a ciência, saindo da visão de educação como meio de desenvolvimento da razão no seu sentido técnico-instrumental. Além disso, uma educação que precisa atingir os diferentes saberes não deve hierarquizá-los. Tal ideia de hierarquizar saberes parte do paradigma moderno que reconhece os conhecimentos científicos como verdades absolutas, descartando qualquer outro saber. Para Jesus (2004, p. 121), "esta ciência se desenvolve pela fragmentação do conhecimento em disciplinas isoladas e pela hierarquização do que julga ser mais ou menos importante de acordo com as exigências hegemônicas econômicas e de poder". Tão agravante quanto isso, segundo a autora, é desqualificar esses conhecimentos e práticas da tradição dos que vivem no campo, colocando-os como atrasados. Assim, tanto a ciência não deve intitular-se como uma detentora de verdades absolutas e imutáveis, quanto os saberes populares não devem fechar-se em si mesmos (JESUS, 2004).

Observa-se que os alunos camponeses possuem uma ligação com a base material desenvolvida em comunidade e, dessa forma, possuem vivências, formas de se expressar e maneiras de entender o mundo diferentes das privilegiadas na escola. A escola ou o professor de uma dada disciplina que não valorize isso não tratará os conteúdos seguindo um possível currículo construído junto a eles, mas sim seguindo a lógica imposta pela ideologia dominante que nada tem a ver com as necessidades dessa comunidade. Portanto, de acordo com Chassot (2003, p. 13), não se pode mais conceber o ensino de Ciências sem incluir nos currículos elementos interligados com os aspectos sociais e pessoais dos estudantes, ou seja, é preciso dar ao ensino "uma postura mais holística que contemple aspectos históricos, dimensões ambientais, posturas éticas e políticas, mergulhados na procura de saberes populares e na dimensão da etnociências". 


\section{CONTEÚDOS PRIORIZADOS}

A partir dos critérios de seleção dos conteúdos e dos conhecimentos de referência definidos pelos professores, tentou-se compreender como isso ocorre, mais especificamente, com os conteúdos escolares da disciplina em questão. Assim, foi solicitado, em uma das perguntas do questionário, que os professores listassem os assuntos de Ciências mais importantes para se lecionar aos alunos do Ensino Fundamental de suas escolas do campo. Então, elaboramos uma lista unindo estes com os assuntos citados em algum momento das entrevistas. No sexto ano, citaram: diferentes ecossistemas, solos, água, reciclagem, clima local, relação homem-natureza. Referente ao sétimo ano, foram os seguintes conteúdos: fauna e flora local. No oitavo ano, foram citados: educação sexual, higiene corporal e alimentação.

Para escolha desses assuntos, os professores apresentaram as mais variadas justificativas no questionário, sendo compatíveis com as coletadas durante as entrevistas, em relação à proximidade com a realidade dos educandos. Ao analisar os conteúdos priorizados, observa-se que os professores percebem o sexto ano como sendo aquele mais ligado ao contexto do campo, destacando a natureza e os seus recursos físicos - o solo, o clima e a água -, bem como a influência e relação com o homem. No entanto, devido a essa percepção, seria mais provável que o sétimo ano também fosse lembrado por eles, mas essa série foi citada por apenas um professor. Assim, deixaram de fora a biodiversidade local. No oitavo ano, destacaram a alimentação, talvez por ser algo mais ligado ao trabalho na agricultura desempenhado pelos alunos. Vale frisar a necessidade de se interligar esse conteúdo com os já citados, bem como com qualquer questão que envolva o corpo humano - sistemas e doenças que o acometem. Os conteúdos mais ligados à Química e à Física foram esquecidos pelos educadores, deixando de fora questões como, por exemplo, os produtos químicos diariamente utilizados pelos estudantes.

Como em nenhum momento eles questionavam a formulação desse currículo escolar que seguiam, perguntamos se o currículo das suas escolas do campo deixava de englobar algum aspecto ou de ensinar algo aos alunos. Todos responderam que não, mostrando, mais uma vez, a falta de criticidade sobre os elementos escolares que os são dados a trabalhar. Contrariam, então, a proposta de Moreira e Candau (2003, p. 163) de ampliar os conteúdos curriculares:

de modo a neles incluir a crítica dos diferentes artefatos culturais que circundam o(a) aluno(a). A idéia é transformar a escola em um espaço de crítica cultural, de modo que cada professor(a), como intelectual que é, possa desempenhar o papel de crítico(a) cultural.

Dessa forma, ainda segundo Moreira e Candau (2003, p. 163), estariam propiciando ao estudante a compreensão de que "tudo que passa por 'natural' e 'inevitável' precisa ser questionado e pode, conseqüentemente, ser 
transformado". Isso acontece porque as poucas escolas existentes na zona rural são escolas que apenas estão no campo, apresentando, segundo Nascimento (2002), um projeto político-pedagógico desvinculado às causas, aos desafios, aos sonhos, à história e à cultura do povo do campo. Esse autor afirma ainda que são escolas relegadas ao abandono, com docentes desqualificados e com visão de mundo urbano, currículo e calendário escolar alheios à realidade do campo, onde suas escolas estão inseridas.

Ser um trabalhador da terra é compreender a dinâmica da natureza, é depender diretamente de uma relação sustentável com o ambiente para conseguir sua subsistência. Portanto, segundo Fernandes (2004, p. 101), "o campo é espaço e território dos camponeses e dos quilombolas. É no campo que estão as florestas, onde vivem as diversas nações indígenas. Por tudo isso, o campo é lugar de vida e de Educação", onde esses dois termos não podem andar separados. Dessa forma, o ensino de Ciências no campo precisa levar em consideração quais os conhecimentos científicos são mais relevantes para promover soluções da problemática encontrada nesse local, bem como valorizar práticas da tradição dos camponeses. Necessita, ainda, auxiliar na emancipação desses sujeitos quando passarem a compreender o ambiente que os cercam, adquirindo autonomia. Isso só é possível quando se estabelece o diálogo entre o saber de tradição e o saber científico, objetivando construir o saber escolar do campo.

Depois de entender como ocorre a definição do currículo escolar, indagamos se os professores se sentiam preparados para abordar esses assuntos necessários para os alunos de modo a transformá-los em pessoas críticas e reflexivas sobre o meio onde vivem, efetivando-se a alfabetização científica. Ao responder: "Nasci, cresci e adquiri conbecimento no dia a dia neste ambiente, como também me preparei academicamente", o professor 2 acredita estar preparado para os desafios docentes exigidos, valorizando os saberes cultural e científico.

Lembrando-se apenas do quesito saber científico, outros dois professores afirmaram estar preparados para desenvolver o currículo de Ciências em suas escolas. De modo oposto, dois professores afirmaram não se sentirem preparados para desempenhar tal função pelo despreparo acadêmico. Como lembra Monteiro (2001), é presente no imaginário de muitos educadores a ideia de que basta possuir conhecimento científico para se formar um professor. Esse raciocínio nega a subjetividade do professor como agente no processo educativo e o fato de que a atividade docente lida com, é dependente de e cria conhecimentos tácitos, pessoais e não sistemáticos que só podem ser adquiridos pelo contato com a prática, além de esquecer dos estudos culturais e da sociologia que veem o currículo como terreno de criação simbólica e cultural. De modo complementar, Portilho (2006) traz a hipótese de que os cursos de formação de docentes não dão conta da profundidade que a complexa realidade do campo vem a requerer no contexto atual dos seus grandes dilemas e embates contemporâneos. Isso também é reforçado por Fernandes (2004) ao referir-se à falta de formação de professores adequada a essa realidade. 


\section{CONCLUSÃO}

Mais do que em qualquer outro lugar, a comunidade inserida no meio rural é a mais privilegiada no entendimento sobre as necessidades de um efetivo desenvolvimento sustentável - no consumo de bens materiais e naturais. Isto porque os povos do campo interagem diariamente com a natureza, não separam ambiente natural de relações sociais. Além disso, presenciam constantemente os fenômenos naturais, sentindo suas consequências. Isso, a priori, poderia nos levar a inferir que a disciplina em questão deve priorizar esses aspectos.

Porém, os professores de Ciências pesquisados demonstraram uma centralidade no livro didático, mesmo quando alguns percebem sua deficiência. Então, o currículo é produzido por eles a partir de uma seleção dos conteúdos do livro adotado, trazendo o que eles definem como sendo mais relevante para o contexto dos alunos ou o que mais apresenta afinidade. Entretanto, ao elaborarem justificativas para a escolha dos assuntos, os professores apresentaram uma visão utilitarista e reducionista no ensino de Ciências. Isto é, não veem o currículo escolar dessa disciplina como espaço de produção cultural, no qual conceitos, identidades e atitudes são praticados.

Isso é preocupante se considerarmos que a educação posiciona os atores dependendo da relação que eles têm com os saberes hegemônicos desenvolvidos de maneira independente das necessidades de cada contexto dos alunos. Se quisermos estabelecer uma mudança, tanto os professores quanto os alunos precisam desempenhar papéis que modifiquem essa realidade descrita anteriormente. Aos professores, cabe o papel de reflexão sobre a prática, de modo a torná-la um meio de construção de saberes, não de qualquer saber, mas sim de saberes significantes.

Se poucos professores demonstraram pequenos avanços ao preocuparem-se com um currículo a partir do contexto local e que questionasse as práticas cotidianas em comunidade, consideramos que essa não seja uma prática intencional, fazendo-se isso apenas para tornar o conteúdo ensinável. O necessário é que essas escolas do campo adotem uma política pedagógica apropriada, construindo um currículo que responda aos questionamentos que os camponeses apresentem, que dê voz à cultura local, que contribua na (des)construção das práticas culturais.

\section{REFERÊNCIAS BIBLIOGRÁFICAS}

ARROYO, M. Por um tratamento público da Educação do Campo. In: MOLINA, Mônica C; JESUS, Sonia M. A. de. (org.). Contribuiçoes para a construção de um projeto de Educação do Campo. Brasília, DF: [s.n], 2004. AULER, D.; DELIZOICOV, D. Alfabetização Científico-Tecnológica para quê? Ensaio-Pesquisa em Educação em Ciências, Belo Horizonte, vol. 03. n. 1, Jun. 2001.

BATISTA, M. S. X. ; MORAES, V. A. Movimentos sociais e a educação do campo: um projeto de educação para o desenvolvimento sustentável do campo. In: SEMINARIO LUSO-BRASILEIROCABOVERDIANO (SEMILUSO), 1. João Pessoa. Anais... João Pessoa: Editora UFPB, 2008, p. 1-20. BERNSTEIN, B. A Estruturação do Discurso Pedagógico: classe, códigos e controle. Petrópolis, RJ: Vozes, 1996. 
BRASIL. Indicadores Demográficos e Educacionais de 2008. Brasília: MEC, 2008. Disponível em: <http:/ / portal.mec.gov.br/ide/layout_tabelas/gerarTabelas.php>. Acesso em: 12 set. 2008.

CONFERÊNCIA NACIONAL POR UMA EDUCAÇÃO DO CAMPO, 2, 2004, Luziânia. Declaração final. Luziânia: CNEC, 2004. 6 p.

CALDART, R. S. A Escola do Campo em Movimento. In: ARROYO, M. G.; CALDART, R. S.; MOLINA, M. (org.). Por uma Educação do Campo. Petrópolis, RJ: Vozes, 2004.

. A Escola do Campo em movimento. Currículo sem Fronteiras, Porto Alegre, v.3, n.1: 2003 p. 60-81

CARNEIRO, M. H. S.; MÓL, Wildson Luiz Pereira S. Livro didático inovador e professores: uma tensão a ser vencida. Ensaio - Perspectivas em Educação em Ciências, Florianópolis, v. 7, n. 2, dezembro 2005. CHASSOT, A. Alfabetização científica: uma possibilidade para a inclusão social. Revista Educação Brasileira, Rio de Janeiro, n. 22, jan./abr. 2003.

CHEVALLARD, Y. La Transposición didáctica: Del saber sabio al saber enseñado. Buenos Aires: AIQUE, 1991. DELIZOICOV, D.; ANGOTTI, J. A.; PERNAMBUCO, M. M. Ensino de Ciências: fundamentos e métodos. São Paulo: Cortez, 2002.

EL-HANI, C.; SEPÚLVEDA, C. Referenciais Teóricos e Subsídios Metodológicos para a Pesquisa sobre as Relações entre Educação Científica e Cultura. In: SANTOS, F.; GRECA, I. (Org.). A Pesquisa em Ensino de Ciências no Brasil e suas Metodologias. Ijuí, RS: UNIJUI, v. 1, 2006 p. 161-212.

FERNANDES, B. M. Diretrizes de uma caminhada. In: ARROYO, M. G.; CALDART, R. S.; MOLINA, M. C. (org.) Por uma Educação do Campo. Petrópolis, RJ: Vozes, 2004.

FLICK, Uwe. Uma introdução à pesquisa qualitativa. Porto Alegre, RS: Artes Médicas, 2002.

FREIRE, P. Pedagogia da Esperança: um reencontro com a pedagogia do oprimido. Rio de Janeiro: Paz e Terra, 1992.

GOODSON, I. F. Currículo: teoria e história. Rio de Janeiro: Vozes, 1995.

GIROUX, H. A. Praticando estudos culturais nas faculdades de educação. In: SILVA, Tomaz T. (org.). Alienigenas na sala de aula: uma introdução aos estudos culturais em educação. Rio de Janeiro: Vozes, 1995. JESUS, S. M. S. A. Questões paradigmáticas da construção de um projeto político pedagógico da Educação do Campo. In: MOLINA, M.; JESUS, S. (org.). Contribuições para a construção de um projeto de Educaşão do Campo. Brasília, DF: [s.n], 2004.

KRASILCHIK, M.; MARANDINO, M. Ensino de Ciências e Cidadania. São Paulo: Moderna, 2004.

LOPES, A. C. Políticas curriculares: continuidade ou mudança de rumos?. Revista Brasileira de Educação, São Paulo, v. 1, n. 26, p. 109-118, 2004.

Políticas de currículo: lutas para definir o conhecimento escolar. In: PACHECO, J. A.; MORGADO, J. C.; MOREIRA, A. F. B. (Org.). Globalização e (des)igualdades: desafios contemporâneos. V. 1, Porto: [s.n], 2007. p. 163-174.

Conhecimento escolar: processos de seleção cultural e de mediação didática. Educaşão \& Realidade, Porto Alegre, v. 22, n. 1, p. 95-112, 1997

MAIA, E. M. A qualidade do ensino básico na zona rural: problemas de administração descentralizada num contexto autoritário. Cadernos de pesquisa, São Paulo, n. 46, p. 16-22, 1983.

MACEDO, E. Currículo: política, cultura e poder. Currículo sem Fronteiras, Porto Alegre, v.6, n.2, p.98-113, Jul/Dez 2006.

. A imagem da ciência: folheando um livro didático. Educaşão e Sociedade, Campinas, vol. 25, n. 86, p. 103-129, abril de 2004.

MARCONI, Marina de Andrade; LAKATOS, Eva Maria. Fundamentos da metodologia científica. 6 ed. São Paulo: Atlas, 2006. 215 p.

MARTÍ, J. O Campo da Educação do Campo. In: MOLINA, M.; JESUS, S. (org.). Contribuições para a construção de um projeto de Educação do Campo. Brasília: [s.n], 2004.

MAZZOTTI, Alda Judith Alves; GEWANDSZNAJDER, Fernando. O Método das Ciências Naturais e Sociais: Pesquisa Quantitativa e Qualitativa. 2. ed. São Paulo: Pioneira, 1999.

MONTEIRO, A. M. F. C. Professores: entre saberes e práticas. Educação \& Sociedade, Campinas, SP, vol. 22, n. 74, Abr. 2001.

MOREIRA, A. F.; CANDAU, V. M. Educação escolar e cultura(s): construindo caminhos. Revista Brasileira de Educação, São Paulo, n. 23, p. 156-168, ago. 2003. 
MOREIRA, A. F.; SILVA, T. T. Sociologia e teoria crítica do currículo: uma introdução. In: (org.) Currículo, Cultura e Sociedade. São Paulo: Cortez. 1995. p. 7-38.

NASCIMENTO, G. O livro de Biologia no ensino de biologia. 2002. Dissertação (Mestrado em Biologia) - Faculdade de Educação, Universidade de Brasília, Brasília, UNB, 2002.

Nuñez, I. B. A seleção dos livros didáticos: um saber necessário ao professor: o caso do Ensino de Ciências. OEI-Revista Iberoamericana de Educación v. 3, p. 3-15, 2005. Disponível em: <http:// www.rieoei.org/deloslectores/427Beltran.pdf>. Acesso: maio 2008.

PORTILHO, E. Escola e realidade do campo: o caso do Centro de Ensino fundamental Pipiripau II. 2006. Dissertação (Mestrado) - Universidade de Brasília, Brasília, UNB, 2006.

SANTOS, L. P.; PARAÍSO, M. A. O currículo como campo de luta. Revista Presença Pedagógica, Belo Horizonte, v. 2, n. 7, p. 33-39, jan./fev. 1996.

SILVA, T. T. Documentos de Identidade: uma introdução às teorias de currículo. 2ed. Belo Horizonte: Autêntica, 2002.

Identidades terminais: As transformações na política da pedagogia e na pedagogia da política. Petrópolis: Vozes, 1996. 